\title{
RESEARCH
}

Open Access

\section{Self-reported vs. objectively assessed adherence to inhaled corticosteroids in asthma}

\author{
Frodi Fridason Jensen ${ }^{1 \dagger}$, Kjell E. J. Håkansson ${ }^{1 *+}$ D, Britt Overgaard Nielsen², Ulla Møller Weinreich ${ }^{2,3}$ and \\ Charlotte Suppli Ulrik ${ }^{1,4}$
}

\begin{abstract}
Background: Adherence to inhaled corticosteroids (ICS) in asthma is vital for disease control. However, obtaining reliable and clinically useful measures of adherence remains a major challenge. We investigated the association between patient-reported adherence and objectively measured adherence based on filled prescriptions with inhaled corticosteroids in adults with asthma.

Methods: In total, 178 patients with asthma were asked to self-assess adherence during routine visits at a respiratory outpatient clinic. Self-assessment was performed using Foster score ("How many days in a 7-day week do you take your medication as prescribed?", with the answer divided by 7). Objective adherence was calculated as medication possession ratio (MPR). Bivariate and multivariable linear regression, adjusted for age, sex, FEV ${ }_{1}, \mathrm{GINA}$ treatment step, excessive use of SABA, and history of exacerbations were used for analyses.

Results: Of the included patients, $87.6 \%$ reported a Foster score of 100\%, while the mean ICS MPR was 54.0\% (SD 25\%). Complex regimens such as twice-daily dosing or dual inhaler-use were associated with lower adherence ( $p=$ 0.015 and $p<0.001$, respectively).

Foster score was predictive of ICS MPR, with an absolute 32\% increase in MPR between patients reporting Foster scores of 0 and $100 \%$ (95\% Cl 13-50\%, $p<0.001)$. Female sex predicted higher ICS MPR $(p=0.019)$. Previous asthma-related hospitalization(s) predicted lower ICS MPR ( $p=0.039)$.

Conclusion: Although a weak association was found between Foster score and ICS MPR, findings do not support the use of Foster score, and by that self-reported adherence, as a reliable marker of controller adherence in asthma due to significant mismatch between patient-reported adherence and MPR. Future studies should address the complex interplay between patient-reported and objectively assessed adherence to controller medication in asthma.
\end{abstract}

Keywords: Foster score, Medication possession ratio, Controller medication, Asthma, Self-assessed adherence, Patient-reported outcome

* Correspondence: kjell@kjell.dk

${ }^{\dagger}$ Frodi Fridason Jensen and Kjell E. J. Håkansson contributed equally to this work.

${ }^{1}$ Department of Respiratory Medicine, Copenhagen University Hospital -

Hvidovre, Hvidovre, Denmark

Full list of author information is available at the end of the article

C The Author(s). 2021 Open Access This article is licensed under a Creative Commons Attribution 4.0 International License, which permits use, sharing, adaptation, distribution and reproduction in any medium or format, as long as you give appropriate credit to the original author(s) and the source, provide a link to the Creative Commons licence, and indicate if changes were made. The images or other third party material in this article are included in the article's Creative Commons licence, unless indicated otherwise in a credit line to the material. If material is not included in the article's Creative Commons licence and your intended use is not permitted by statutory regulation or exceeds the permitted use, you will need to obtain permission directly from the copyright holder. To view a copy of this licence, visit http://creativecommons.org/licenses/by/4.0/. The Creative Commons Public Domain Dedication waiver (http://creativecommons.org/publicdomain/zero/1.0/) applies to the data made available in this article, unless otherwise stated in a credit line to the data. 


\section{Quick look}

\section{Current knowledge}

Assessing adherence to ICS is central to asthma care with a plethora of assessment methods, yet a lack of standardization in clinical use. A verified, reliable patient-assessed method with acceptable correlation to objective measurements of adherence is yet to be established. In Danish national guidelines, the one-item questionnaire Foster score is recommended for use in adherence assessment without a clear correlation to clinical outcomes.

\section{What this paper contributes to our knowledge}

Our findings suggest that the routinely used, patientreported Foster score correlates poorly to objective measures of adherence when used in clinical practice. Furthermore, it builds on current evidence that objective, clinical parameters are insufficient to explain patterns of adherence. Furthermore, subjective factors and treatment regimens are important elements in asthma controller adherence and needs to be individually addressed beyond the use of simple scores.

\section{Introduction}

Asthma is one of the most common chronic diseases and impacts patients throughout their lives [1-3]. With appropriate diagnostic workup and pharmacologic treatment, a large proportion of patients can achieve symptom control and a low risk of adverse events, such as acute exacerbations. Treatment with inhaled corticosteroids (ICS) reduces symptoms, improves pulmonary function parameters such as forced expiratory volume in $1 \mathrm{~s}\left(\mathrm{FEV}_{1}\right)$, reduces risk of future exacerbations and asthma-related mortality [4-6]. However, adherence to controller medication, including ICS, is highly variable between asthma patients and is estimated to range between 22 to $70 \%$ of prescribed doses across different settings $[2,7,8]$. Possible reasons for non-adherence to asthma controller therapy are numerous and are often related to lack of perceived need for treatment and/or either fear of side effects or perceived side effects of ICS treatment [9]. However, not all reasons for nonadherence are based on personal beliefs or even intentional, as social factors outside of the patient's own control, forgetfulness and misunderstandings have been shown to be significant contributors to non-adherence [7].

Low adherence to controller medication is associated with poor disease control and adverse outcomes in asthma. These include higher symptom burden, lower $\mathrm{FEV}_{1}$ and higher risk of hospitalization-requiring exacerbations [2]. As such, it is vital to address poor adherence, even though the complexity of factors associated with reduced adherence is daunting to clinicians and patients are reluctant to admit non-adherence [10]. Nonetheless, patients must be engaged in a discussion during consultations, as improving adherence requires a multimodal approach and establishing a partnership with patients [11]. To this end, clinically reliable tools for quick adherence assessments, both objective and subjective, are needed.

Adherence can be estimated objectively using several methods with electronic dose metering being the current gold standard for ICS adherence measurement [12, 13]. The Medication Possession Ratio (MPR), based on prescription data, is another method for measuring objective adherence, one that does not require access to specialized inhaler equipment. With regard to patientreported adherence, the Danish Society of Respiratory Medicine's Guidelines on Possible Severe Asthma recommends the systematic use of Foster score when assessing adherence [14]. The Foster score was developed as a simple, non-confrontational, one question scoring method for quick assessment based on the Morisky medication-taking behavior scale [9, 15]. However, its clinical value and relationship to objective adherence measurement remains unclear.

In the present study, we aimed to investigate the correlation between patient reported adherence assessed by Foster score and the objectively measured MPR in a university hospital asthma outpatient clinic.

\section{Methods}

\section{Design, Study Population \& Participant Enrolment}

This study is a cross-sectional observational study carried out in the Respiratory Outpatient Clinic, Department of Respiratory Medicine, Copenhagen University Hospital - Hvidovre, Hvidovre, Copenhagen, Denmark.

All patients with a routine follow-up appointment between January and June 2020 at the Respiratory Outpatient Clinic with an active asthma ICD-10 code (DJ45) were screened for inclusion using electronic patient medical records. Cohort inclusion required the following criteria: i) objectively confirmed asthma for at least 12 months prior to inclusion ii) at least 18 years of age. Exclusion criteria were as follows: i) patients prescribed ICS for less than 12 months at the index date, ii) recipients of dose dispensed medications via assisted care, iii) the inability to answer the questionnaire due to any psychological or physical limitations and iv) non-Danish residents without a Danish civil registration number and corresponding Common Medication Card.

\section{Ethics}

The present study was approved by the Danish Patient Safety Authority (ref. 31-1521-118) and the Capital Region of Copenhagen's Data Monitoring Board (ref. P-2020-648). 


\section{Data collection}

Data for age, sex, body mass index (BMI), Fractional Exhaled Nitric Oxide (FeNO), lung function parameters $\left(\mathrm{FEV}_{1}, \mathrm{FEV}_{1} \%\right.$ pred, Forced Vital Capacity (FVC) and FVC\%pred) and Asthma Control Questionnaire 6-score (ACQ6) was collected through electronic medical records (Sundhedsplatformen, Epic Systems Inc., USA).

Asthma exacerbation data was collected from electronic patient journals using the following definitions: i) Moderate exacerbation - either prescription of at least $37.5 \mathrm{mg}$ oral prednisolone for at least 3 days not coinciding with a hospitalization, or hospitalization/emergency room admittance for less than $24 \mathrm{~h}$. ii) Severe exacerbation - any exacerbation requiring hospitalization for at least $24 \mathrm{~h}$ and administration of oral or intravenous corticosteroids.

\section{Spirometry}

Lung function was measured using a Pneumotrac (Vitalograph Ltd., Buckinghamshire, UK) spirometer as part of standard of care at the respiratory outpatient clinic.

\section{Allergies}

Patients were considered to have allergic disease when 1) relevant symptoms and 2) relevant diagnostic workup (either positive skin prick test, blood samples positive for elevated specific Immunoglobulin E (IgE) or elevated total-IgE) were described in the electronic patient records.

\section{Prescription data}

Pharmacy redemption data was collected for each patient from the national Common Medication Card, the national prescription register for the tax-funded universal healthcare insurance in Denmark. ICS, long-acting $\beta 2$-agonist (LABA), long-acting muscarinic receptor antagonist (LAMA), leukotriene-receptor antagonist (LTRA), short-acting $\beta 2$-agonist (SABA), theophylline, biologic therapy (anti-IL5(Ra), anti-IL4/13 and anti-IgE), oral corticosteroid (OCS) doses and proton-pump inhibitor (PPI) use was registered for 12 months prior to the index date.

Daily prescribed ICS dose was categorized according to the GINA 2020 guidelines [6]. Objective controller medication adherence (MPR) was calculated as the number of physician prescribed doses during the previous 12 months, divided by the number of redeemed doses during the previous 12 months [16]. During MPR calculations, the following adjustment were performed i) Patients prescribed two ICS inhalers were considered to be adherent to treatment if both doses were available for use at the same time. ii) For patients with dual ICS therapy prescriptions, only redeeming one of the ICS during the observation period, MPR was calculated as single
ICS MPR for the inhaler redeemed and reduced by $50 \%$ to reflect non-adherence. iii) Patients changing inhalers during the observation period had the remainder of doses in the discontinued inhaler at the date of discontinuation discarded to prevent inflation of MPR.

\section{Patient reported adherence}

Ten modifiable patient beliefs or behaviors regarding adherence to ICS has been identified by Foster and colleagues [9]. Based on the results of Foster et al. [9], a socalled Foster score has been adapted and recommended by the Danish Society of Respiratory Medicine Guidelines using the question "How many days in a 7-day week do you take your medication as prescribed?". The Foster score is achieved by dividing the patients' answer by seven and multiplying by 100 . The resulting Foster score ranges from $0 \%$ (completely non-adherent) to $100 \%$ (fully adherent).

\section{Inhaler technique}

All patients enrolled had inhaler technique, including inspiratory flow and device handling, assessed at both the index visit as well as any prior visits to ensure proper inhaler use.

\section{Statistics}

Descriptive statistics were used to generate demographic data, with the results presented as means with standard deviations (SD). Groupwise comparisons, including nonresponder analyses, were performed using either t-tests or Wilcoxon rank-sum tests, depending on the distribution of the data.

Non-responder analyses were performed, comparing demographics and asthma-related parameters of patients who provided clinicians with a Fosters score to those whose Foster scores were not recorded in their patient records.

Bivariate and multivariable linear regressions were performed to investigate the association between Foster score and MPR. Multivariable linear regression analyses were adjusted for age, $\mathrm{FEV}_{1}$, sex, GINA 2020 treatment step [6] number of hospitalizations due to asthma the past 24 months, prescribed oral corticosteroids and SABA overuse (defined as $\geq 600$ doses per year).

Explorative multivariable linear regression was performed to assess the influence of common comorbidities and subjective disease control on Foster scores and ICS MPR. The model was adjusted for age, sex, ACQ6, BMI, GERD (Gastroesophageal reflux disease, defined as PPIuse at the index visit) and allergy. A $p$-value of 0.05 was considered as statistically significant.

R 4.0.0 (The R Foundation for Statistical Computing) was used for statistical analysis and to generate figures. 


\section{Results}

A total of 400 patients were screened in the respiratory outpatient clinic during the inclusion period, of which 313 were eligible for the study. Out of the 313 eligible patients, 135 patients failed to supply Foster scores during consultations and were thus excluded. The final cohort comprised of 178 patients, of whom 136 (76.4\%) were female, and the mean age was 47 (SD 16) (Table 1).

\section{Lung function, comorbidities and asthma severity}

In the final cohort, mean FEV1 was 91\%pred (SD 18), corresponding to $2.79 \mathrm{~L}$ (SD 0.80) (Table 1). Mean BMI and FeNO were 27.6 (SD 5.8) and 20.3 ppb (SD 18.9), respectively. Fifty-nine patients $(36.7 \%)$ were classified as having allergic disease and 41 patients $(23.0 \%)$ were prescribed PPI for GERD.

When classified according to GINA 2020 severity 15 (8.4\%), 60 (33.7\%) and 103 (57.9\%) were classified as mild, moderate and severe, respectively (Table 1).

Table 1 Baseline characteristics of the study sample comprising 178 patients with asthma managed at a university hospital respiratory outpatient clinic

\begin{tabular}{ll}
\hline Baseline Characteristics & N (\%) or Mean (SD) \\
\hline Age (yrs.) & $47(16)$ \\
Female & $136(76.4 \%)$ \\
ACQ6-score & $1.32(1.07, N=114)$ \\
FeNO & $20.3(18.8, N=164)$ \\
BMI & $27.6(5.8, N=176)$ \\
Allergic Disease & $59(36.7 \%, N=164)$ \\
GERD & $41(23.0 \%)$ \\
FEV ${ }_{\mathbf{1}}$ (L) & $2.79 \mathrm{~L}(0.80)$ \\
FEV $_{\mathbf{1}} \%$ pred & $91 \%(18 \%)$ \\
FVC (L) & $3.67 \mathrm{~L}(1.02, N=169)$ \\
FVC\%pred & $102 \%(20, N=169)$ \\
FEV /FVC $_{\text {History of Moderate Exacerbations* }}^{*}$ & $0.76(0.09, N=169)$ \\
24-month Moderate Exacerbation Rate & $43(24.2 \%)$ \\
History of Severe Exacerbations** & $1.77(1.27)$ \\
24-month Severe Exacerbation Rate & $23(12.9 \%)$ \\
GINA 2020 Asthma Severity Grade & $1.65(1.50)$ \\
Mild Disease & \\
Moderate Disease & $15(8.4 \%)$ \\
Severe Disease & $60(33.7 \%)$ \\
\hline
\end{tabular}

*defined as either prescription of at least $37.5 \mathrm{mg}$ oral prednisolone for at least 3 days, or hospitalization/emergency room admittance for less than $24 \mathrm{~h}$ in the last 24 months prior to inclusion. ${ }^{* *}$ defined as any exacerbation requiring hospitalization for at least $24 \mathrm{~h}$ and administration of oral or intravenous corticosteroids. $N$ number of patients, yrs. years, ACQ Asthma Control Questionnaire, BMI Body Mass Index, FeNO Fractional Exhaled Nitric Oxide, FEV ${ }_{1}$ Forced Expired Volume in the first second, GERD Gastroesophageal Reflux Disease, GINA Global Initiative for Asthma
Regarding ICS doses, medium and high doses were prescribed to $71(39.9 \%)$ and $41(23.0 \%)$ patients, respectively (Table 2).

\section{Asthma control}

In terms of disease control, 43 (24.2\%) patients had had moderate exacerbations during the past 24 months. For patients with at least one moderate exacerbation, the mean 24-month moderate exacerbation rate was 1.77 (SD 1.27).

Of the included patients, 23 had been hospitalized due to an asthma exacerbation with a mean 24-month hospitalization rate of 1.65 (SD 1.50).

The mean annual SABA use was 255 (SD 445) doses/ year, with $18.0 \%$ of patients defined as having an excessive SABA use above 600 doses/year (Table 2).

Table 2 Treatment regimens and patient-reported and objectively measured asthma medication adherence in 178 patients attending a university hospital outpatient clinic

\begin{tabular}{ll}
\hline Treatment and Adherence & N (\%), Mean (SD) \\
\hline ICS Prescribed Dose & $66(37.1 \%)$ \\
Low Dose & $71(39.9 \%)$ \\
Moderate Dose & $41(23.0 \%)$ \\
High Dose & $32(18.0 \%)$ \\
Dual ICS Therapy & \\
GINA 2020 Step & $15(8.4 \%)$ \\
Step 2 & $60(33.7 \%)$ \\
Step 3 & $62(34.8 \%)$ \\
Step 4 & $41(23.0 \%)$ \\
Step 5 & $3(1.7 \%)$ \\
Biologic Therapy & $6(3.4 \%)$ \\
Maintenance Oral Corticosteroids & $255(445)$ \\
Annual SABA Use (Doses) & $32(18.0 \%)$ \\
of which > 600 doses/yr & $94.0 \%(19.0 \%)$ \\
Foster Score & $156(87.6 \%)$ \\
of which 100\% & $0.54(0.25)$ \\
Inhaled Corticosteroid MPR & $67.0 \%(13.1 \%)$ \\
Once-daily ICS MPR $(n=19)$ & $53.4 \%\left(25.2 \%, p=0.05^{*}\right)$ \\
Twice-daily ICS MPR $(n=127)$ & $43.9 \%\left(26.0 \%, p=0.02^{*}\right)$ \\
Dual ICS MPR ( $n=32)$ & $30(16.9 \%)$ \\
ICS Adherence & $148(83.1 \%)$ \\
$80 \%$ or above & \\
Below 80\% & \\
\hline
\end{tabular}

* Versus patients receiving once-daily ICS. $N$ number of patients, IQR interquartile range, ICS Inhaled Corticosteroids, GINA Global Initiative for Asthma (2020), MPR medication possession ratio, LABA long-acting $\beta 2$-agonist, LAMA long-acting muscarinic receptor antagonist, $S A B A$ short-acting $\beta 2$-agonist, MPR medication possession ratio, SD standard deviation 


\section{Adherence measurements}

In terms of patient-assessed adherence, the mean reported Foster score was 94.0\% (SD 19.0\%) with 156 (87.6\%) patients reporting the best possible Foster score. Corresponding objective adherence was a mean ICS MPR of $54.0 \%$ (SD 25.0\%), with $16.9 \%$ of patients deemed as being objectively adherent (ICS MPR above $80 \%$ ).

When stratified by ICS treatment regimen as oncedaily, twice-daily or dual ICS, the mean ICS MPR was significantly lower in both twice-daily and dual ICSregimens when compared to patients receiving oncedaily ICS-formulations (Table 2).

Correlation between MPR and patient reported adherence In bivariate regression analysis, a significant association between MPR and Foster score was demonstrated, with an absolute 36\% MPR difference (Beta 0.36, 95\% CI $0.18-0.54 ; p<0.001)$ between patients reporting Foster scores 0 and $100 \%$. However, the model fit was poor $\left(R^{2}\right.$ 0.082 ), even though the overall model demonstrated a significant $p$-value of $<0.001$ (Fig. 1).

In multivariable analysis adjusted for age, $\mathrm{FEV}_{1}$, sex, GINA 2020 treatment step, history of moderate and severe exacerbations in the past 24 months and excessive SABA use, Foster score remained statistically significantly associated with ICS MPR, with an absolute MPR increase of $32 \%$ between patients reporting a Foster score of 0 and 100\% (Beta 0.32, 95\% CI $0.13-0.50 ; p<0.001)$. Female sex was associated with a higher ICR MPR $(0.12$, 95\% CI $0.02-$ $0.22 ; p=0.019)$ while a history of severe exacerbations the past 24 months was associated with a lower ICS MPR (-0.12, 95\% CI -0.24 - -0.01, $p=0.039$ ). Additionally, a trend towards a higher MPR with increasing $\mathrm{FEV}_{1}$ was found $(0.05,95 \% \mathrm{CI}-0.01$ 0.11 , p 0.079). The overall model achieved an adjusted $R^{2}$ of 0.149 with a corresponding $p$-value of 0.001 (Table 3).

\section{Explorative analyses}

In multivariable linear regression adjusted to investigate correlation between ICS MPR, Foster score and the role of comorbidities and patient-reported disease control, Foster score remained associated with ICS MPR though with a neutral beta $(0.00,95 \%$ CI $0.00,0.01 ; p=0.006)$. Of the chosen covariates (age, sex, ACQ6, BMI, GERD and allergic disease) only GERD was significantly associated with ICS MPR (Beta - 0.13, 95\% CI -0.25, - 0.01; $p=0.040$ ) (Table 4).

\section{Non-responder analyses}

Of patients screened for inclusion, participating patients were more likely to be younger, have a slightly lower ACQ and higher lung function variables. However, no

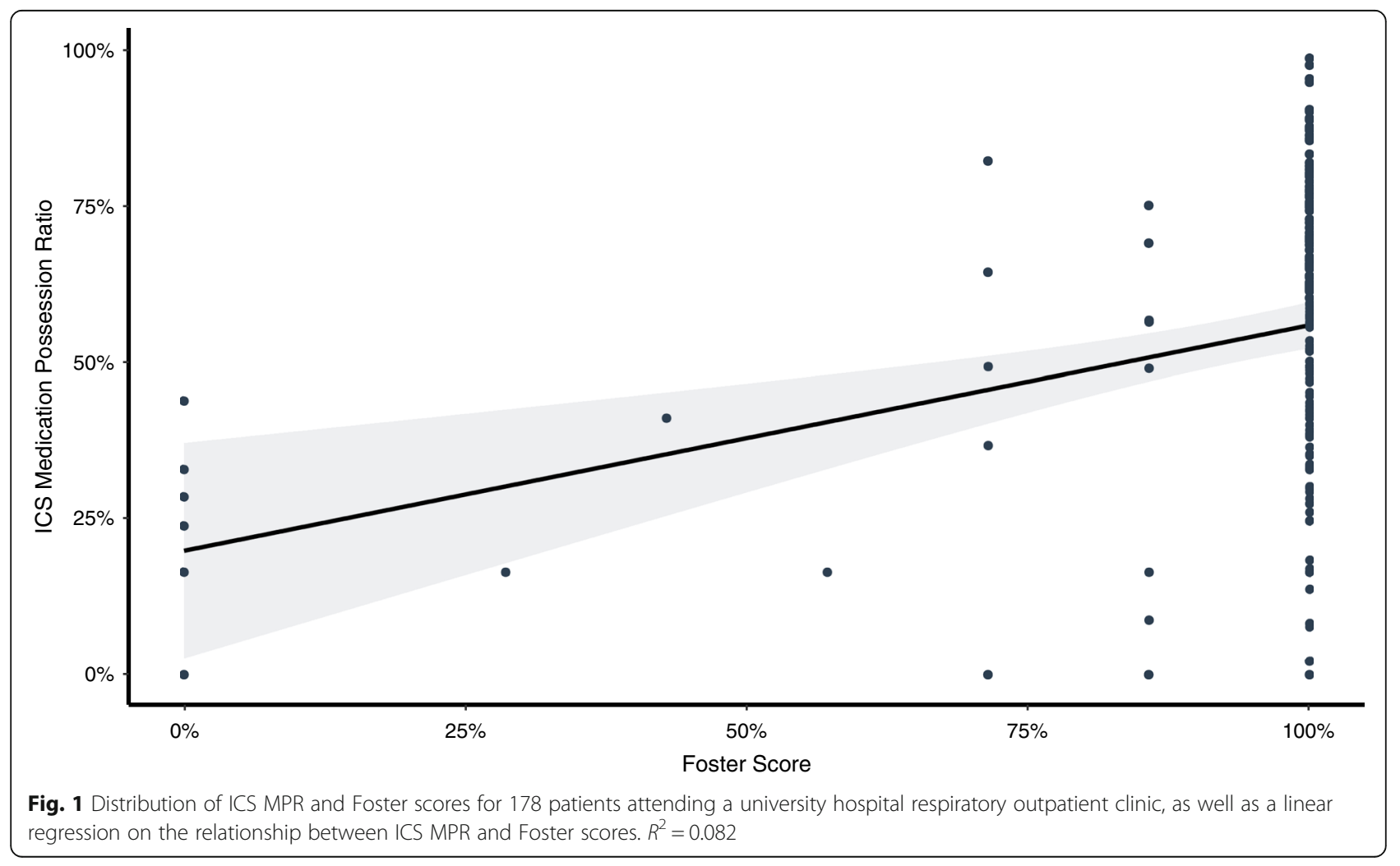


Table 3 Bivariate and multivariable linear regressions with ICS MPR as outcome variable and Foster score, age, FEV 1 , sex, GINA 2020 treatment steps, exacerbation history and excessive SABA use as exposure variables

\begin{tabular}{|c|c|c|c|c|c|c|}
\hline \multirow[t]{2}{*}{ Variable } & \multicolumn{3}{|c|}{ Bivariate } & \multicolumn{3}{|c|}{ Multivariable } \\
\hline & Beta & $95 \% \mathrm{Cl}$ & $P$-value & Beta & $95 \% \mathrm{Cl}$ & $P$-value \\
\hline Foster Score & 0.36 & $(0.18-0.54)$ & $<0.001$ & 0.32 & $(0.13-0.50)$ & $<0.001$ \\
\hline Age & & & & 0.00 & $(0.00-0.00)$ & 0.2 \\
\hline $\mathrm{FEV}_{1}$ & & & & 0.05 & $(-0.01-0.11)$ & 0.079 \\
\hline Female & & & & 0.12 & $(0.02-0.22)$ & 0.019 \\
\hline \multicolumn{7}{|l|}{ GINA 2020 Step } \\
\hline Step 2 & & & & - & - & - \\
\hline Step 3 & & & & 0.02 & $(-0.11-0.16)$ & 0.8 \\
\hline Step 4 & & & & 0.10 & $(-0.04-0.24)$ & 0.2 \\
\hline Step 5 & & & & 0.08 & $(-0.08-0.24)$ & 0.3 \\
\hline History of Moderate Exacerbations ${ }^{\#}$ & & & & 0.00 & $(-0.09-0.10)$ & $>0.9$ \\
\hline History of Severe Exacerbations ${ }^{\# \#}$ & & & & -0.12 & $(-0.24--0.01)$ & 0.039 \\
\hline Excessive SABA use (above 600 doses/yr) & & & & 0.06 & $(-0.04-0.16)$ & 0.3 \\
\hline
\end{tabular}

$R^{2}=0.082$. Adjusted $R^{2}=0.149$. FEV 1 Forced Expired Volume in the first second, GINA Global Initiative for Asthma (2020), \#defined as either prescription of at least $37.5 \mathrm{mg}$ oral prednisolone for at least 3 days, or hospitalization/emergency room admittance for less than $24 \mathrm{~h}$ in the last 24 months prior to inclusion. ${ }^{\# \#}$ defined as any exacerbation requiring hospitalization for at least $24 \mathrm{~h}$ and administration of oral or intravenous corticosteroids, SABA Short-acting beta 2 -agonist

differences in objective disease control measurements or adherence to ICS were found (Supplementary Table 1).

\section{Discussion}

This study sought to investigate the relationship between patient-reported adherence and objective adherence measured by MPR for the past 12 months. Patientreported adherence was high with a mean of $94.0 \%$ and was significantly associated to ICS MPR, though demonstrating a weak direct correlation with overall MPR scores.

We have shown a high prevalence of patients reporting perfect adherence with a Foster score of 100\% despite

Table 4 Multivariable linear regression with ICS MPR as outcome variable and Foster score, age, sex, ACQ6 and common comorbidities (BMI, GERD and allergies) as exposure variables

\begin{tabular}{llll}
\hline Variable & \multicolumn{3}{l}{ Multivariable } \\
\cline { 2 - 4 } & Beta & $\mathbf{9 5 \% ~ C l}$ & $\boldsymbol{P}$-value \\
\hline Foster Score & 0.00 & $(0.00-0.01)$ & 0.006 \\
Age & 0.00 & $(0.00-0.01)$ & 0.061 \\
Female & 0.04 & $(-0.07-0.15)$ & 0.4 \\
ACQ6 & 0.01 & $(-0.04-0.05)$ & 0.8 \\
BMI & 0.00 & $(-0.01-0.01)$ & 0.6 \\
GERD & -0.13 & $(-0.25-0.01)$ & 0.040 \\
Allergy & 0.06 & $-0.05-0.17$ & 0.3
\end{tabular}

Adjusted $R^{2}=0.155$. ACQ6 Asthma Control Questionnaire 6, BMI Body Mass Index, GERD Gastroesophageal reflux (Proton-pump inhibitor-use), Allergy (Relevant symptoms plus either positive skin prick test or elevated specific Immunoglobulin E) high MPR variance (MPR range 0.0-99.7\%). Patient overestimation of adherence is probable, as a significant portion of patients who reported a Foster score of $100 \%$ did not have a corresponding MPR above $80 \%$. Indeed, patient-assessed adherence is vulnerable to social desirability bias and unintentional non-adherence. In accordance with our findings, several studies have found patient-reporting to inflate ICS adherence rates by 30 $90 \%$ [17-19] and similar effects are seen in other chronic diseases [20, 21].

For a patient to be considered adherent, a MPR threshold of $80 \%$ or higher is typically required [2, 22, 23]. In the present study, objectively measured mean adherence (MPR) was in line with previous studies ranging from 8 to $70 \%[2,19,24,25]$. However, we observed a disparity between the number of patients reporting perfect adherence using Foster score (87.6\%) and objectively measured acceptable (MPR $\geq 80 \%$ ) adherence (16.9\%). Such discrepancies are well described in the literature [17], signaling a difference in what is deemed an acceptable level of medication use between clinicians and patients, while highlighting the importance of establishing a partnership with patients and engaging in deeper conversations regarding the use of ICS.

The high prevalence of perfect adherence reported by patients challenges the use of correlation and regression statistics due to high homogeneity and resulting lack of variance and highlights a major weakness in clinical use of the Foster score and limits applicability. However, both regression models demonstrated significant, yet weak, relationships between ICS MPR and Foster score and explained variability 
measured by $R^{2}$ values were low, reaching approximately $15 \%$ in the multivariable model. Foster and colleagues previously investigated the relationship between ICS-related beliefs and MPR and demonstrated that an 11-item model explained two thirds of objective adherence to ICS [9], suggesting that psychological factors represent a larger portion of overall adherence-deciding factors than clinical parameters used in the present study. Other studies have demonstrated that other patient-specific factors, such as socioeconomic status and comorbidity burden, have profound effects on adherence $[7,26]$. Indeed, clinical adherence assessment should include multiple domains, both objective and subjective. Such tools are in continuous development, and the Test of Adherence to Inhalers is a validated example of a multidomain adherence assessment tool [27].

In regression analyses, a history of previous severe exacerbations within the last 24 months was significantly associated with lower adherence. In contrast to a history of severe exacerbations, a history of moderate exacerbations within the last 24 months was not significantly associated with adherence. This suggests that within this population a higher adherence primarily protects against severe exacerbations. The protective effect of ICS adherence on severe exacerbations has been well established $[2,28]$, but recent results and differences in adherence and exacerbation definitions cast doubt on the relationship between adherence, exacerbation history and the risk of future severe, hospitalization-requiring exacerbations [29].

Interestingly, our data suggests that practical factors are associated with adherence, as patients with less complex treatment regimes, such as once-daily dosage, demonstrate a higher MPR than those with twice-daily dosing. Furthermore, the use of more than one ICS inhaler was associated with a lower MPR. This has previously been reported in a plethora of chronic diseases treated with oral medications, showing that one pill taken once-daily is associated with the highest adherence [30]. As such, practical factors are important pieces in the adherence puzzle beyond classic psychological and clinical factors. As such, clinicians should not only take beliefs and disease severity into account when prescribing inhaler treatments, but also gauge individual patients' ability to follow complex regimens.

There are several caveats to using MPR as a measurement of objective adherence. First, the Foster score is a time-agnostic measurement, while MPR always takes a retrospective long-term perspective, demonstrated in the present article by 5 patients reporting a Foster score of 0 while having an MPR above 0 . Second, depending on the chosen methodology MPR measurements are sensitive to inflation when generated from pharmacy records [31]. MPR inflation can occur due to changes in inhaler therapy shortly after treatment initiation, unadjusted dual-ICS therapy (such as a combination of moderate doses of fluticasone and ciclesonide) and redemption of multiple ICS inhalers to use as backup. However, in the present study, MPR inflation has been mitigated in part due to adjusting for inhaler changes by removing excess doses after the physician-ordered discontinuation date, dual-ICS adjustment as well as MPR capping. The use of MPR capping has been thoroughly discussed, with previous studies reporting limited significance of capping MPR, especially in contrast to other adherence measurements such as proportion of days covered $[9,32]$.

\section{Limitations}

Several limitations exist in this study. First, the study covers a set of objective and subjective adherence measurements, reducing generalization to other methods of assessing adherence. Second, while prescription data are accurate in measuring the number of doses redeemed, there is a risk of redeemed doses remaining unused by the patient either due to low adherence or due to a change in medication regimens. Poor inhaler technique may lead to administered but theoretically lower doses which cannot be assessed using MPR, though all outpatients are provided with inhaler training as part of every outpatient visit at the study center. Due to the study design, patients redeeming inhalers in bulk may be either under- or overestimated in terms of number of redeemed doses, should the patient have redeemed multiple prescriptions just outside the study period. Prescription auto-refills are unavailable in Denmark, but have previously been shown to affect adherence with long-term medications and external validity may thus be limited [33]. Furthermore, the cohort has a high prevalence of female participants increasing the risk of bias, though the role of sex in adherence is debated [34] and sex is adjusted for in multivariable analyses. Finally, slight differences between responders and nonresponders was found, however with a large span and with most variables below clinical differences. Outcome measurements such as objective disease control and MPR were not found to be differing between responders and non-responders.

\section{Conclusion}

While a significant association between Foster score and medication possession ratio with inhaled corticosteroids was found, our findings do not support the use of Foster score as the sole marker of adherence with controller medication in asthma. Future studies should address the complex interplay between self-reported and objectively 
assessed adherence with controller medication in asthma.

\section{Supplementary Information}

The online version contains supplementary material available at https://doi. org/10.1186/s40733-021-00072-2.

Additional file 1: Supplementary Table 1. Non-responder analyses of baseline and disease control charateristics of 313 patients eligible for inclusion.

\section{Acknowledgements}

Not applicable.

\section{Authors' contributions}

Literature search (FFJ, KEJH, BO); Data collection (FFJ, KEJH, BO); Study design (KEJH, UMW, CSU); Analysis of data (FFJ, KEJH, BO); Manuscript preparation (FFJ, KEJH, BO, UMW, CSU); Review and approval of the final manuscript (FFJ, $\mathrm{KEJH}, \mathrm{BO}, \mathrm{UMW}, \mathrm{CSU})$. The author(s) read and approved the final manuscript.

\section{Availability of data and materials}

Data is available upon reasonable request. However, approval from data sources and the Capital Region of Copenhagen's Data Safety Board may be required as per Danish law.

\section{Declarations}

Ethics approval and consent to participate

Please refer to the Methods section.

\section{Consent for publication}

Not applicable.

\section{Competing interests}

FFJ, BO and UMW have no conflicts of interest to disclose related to the present article. KEJH reports personal fees and/or travel grants from AstraZeneca, Chiesi and TEVA unrelated to the present article. CSU has received personal fess for oral presentations, advisory board meeting etc. from AstraZeneca, Novartis, GSK, Boehringer-Ingelheim, ALK-Abello, Chiesi, Sanofi, MundiPharma, Actelion, Orion Pharma and TEVA outside the present paper

\section{Author details}

${ }^{1}$ Department of Respiratory Medicine, Copenhagen University Hospital Hvidovre, Hvidovre, Denmark. ${ }^{2}$ Department of Respiratory Diseases, Aalborg University Hospital, Aalborg, Denmark. ${ }^{3}$ The Clinical Institute, Aalborg University, Aalborg, Denmark. ${ }^{4}$ Institute of Clinical Medicine, University of Copenhagen, Copenhagen, Denmark.

Received: 15 March 2021 Accepted: 18 May 2021

Published online: 31 May 2021

\section{References}

1. Knudsen TB, Thomsen SF, Nolte H, Backer V. A population-based clinical study of allergic and non-allergic asthma. J Asthma. 2009;46(1):91-4. https:// doi.org/10.1080/02770900802524657.

2. Bårnes CB, Ulrik CS. Asthma and adherence to inhaled corticosteroids: current status and future perspectives. Respir Care [Internet]. 2015;60(3):45568 Available from: http://www.ncbi.n/m.nih.gov/pubmed/25118311.

3. Papi A, Blasi F, Canonica GW, Morandi L, Richeldi L, Rossi A. Treatment strategies for asthma: reshaping the concept of asthma management. Allergy asthma Clin Immunol [internet]. 2020;16:75 Available from: http:// www.ncbi.nlm.nih.gov/pubmed/32944030.

4. Backer V, Sverrild A, Ulrik CS, Bødtger U, Seersholm N, Porsbjerg C. Diagnostic work-up in patients with possible asthma referred to a university hospital. Eur Clin Respir J. 2015;2(1):27768. https://doi.org/10.3402/ecrj.v2.2 7768 .

5. Kebede B, Mamo G, Molla A. Association of Asthma Control and MeteredDose Inhaler use Technique among adult asthmatic patients attending outpatient clinic, in resource-limited country: a prospective study. Can Respir J. 2019:2019:1-6. https://doi.org/10.1155/2019/6934040.

6. Bateman ED, Hurd SS, Barnes PJ, Bousquet J, Drazen JM, FitzGerald M, et al. Global Strategy for Asthma Management and Prevention. GINA. 2020.

7. George M, Abboud S, Pantalon MV, Sommers MLS, Mao J, Rand C. Changes in clinical conversations when providers are informed of asthma patients' beliefs about medication use and integrative medical therapies. Hear Lung J Acute Crit Care [Internet]. 2016;45(1):70-8 Available from: http://dx.doi.org/1 0.1016/j.hrtlng.2015.11.002

8. Liu C, Tham CW, De Roza J, Chong BY, Koh YL, Tan NC. The association between beliefs and adherence to inhaled controller medication among older adults with asthma: a cross-sectional study in primary care. Patient Prefer Adherence [internet]. 2020;14:1351-9 Available from: http://www. ncbi.nlm.nih.gov/pubmed/32801665.

9. Foster JM, Smith L, Bosnic-Anticevich SZ, Usherwood T, Sawyer SM, Rand CS, et al. Identifying patient-specific beliefs and behaviours for conversations about adherence in asthma. Intern Med J. 2012:42(6).

10. Ulrik CS, Backer V, Søes-Petersen U, Lange P, Harving H, Plaschke PP. The patient's perspective: adherence or non-adherence to asthma controller therapy? J Asthma. 2006;43(9):701-4. https://doi.org/10.1080/0277090060092 5569 .

11. George $M$, Bender B. New insights to improve treatment adherence in asthma and COPD. Patient prefer adherence [internet]. 2019;13:1325-34 Available from: http://www.ncbi.nlm.nih.gov/pubmed/31534319.

12. Pearce CJ, Fleming $\mathrm{L}$. Adherence to medication in children and adolescents with asthma: methods for monitoring and intervention. Expert Rev Clin Immunol. 2018;14(12):1055-63. https://doi.org/10.1080/1744666X.2018.15322 90.

13. Dima AL, van Ganse E, Laforest L, Texier N, de Bruin M. Measuring medication adherence in asthma: development of a novel self-report tool. Psychol Heal [Internet]. 2017;32(10):1288-307 Available from: http://dx.doi. org/10.1080/08870446.2017.1290248.

14. von Bulow A, Ulrik CS, Sidenius K, Bjerrum SA, Christiansen A, Wimmer A, et al. Danish Society of Respiratory Medicine's Guideline on Possible Severe Asthma [Internet]. 2020. [cited 2020 Nov 13]Available from: https://www. lungemedicin.dk/fagligt/384-astma-svær-udredning-og-behandling-af-pa tienter-med-mulig-svær-astma.html

15. Morisky DE, Green LW, Levine DM. Concurrent and Predictive Validity of a Self-Reported Measure of Medication Adherence Author (s): Donald E. Morisky, Lawrence W. Green and David M. Levine Published by: Lippincott Williams \& Wilkins Stable URL: http://www.jstor.org/stable/3764638. Med Care. 1986:24(1):67-74.

16. Vollmer WM, Feldstein A, Smith DH, Dubanoski JP, Waterbury A, Schneider $J$, et al. Use of health information technology to improve medication adherence. Am J Manag Care. 2011;17(SPEC. ISSUE).

17. Osman LM, Hyland ME. Therapeutics: general issues: adherence and selfmanagement. In: Evidence-based respiratory medicine [internet]. Oxford: Blackwell Publishing Ltd; 2007. p. 89-105. Available from: http://doi.wiley. com/10.1002/9780470987377.ch7.

18. Jentzsch NS, Camargos PAM, Colosimo EA, Bousquet J. Monitoring adherence to beclomethasone in asthmatic children and adolescents through four different methods. Allergy Eur J Allergy Clin Immunol. 2009; 64(10):1458-62. https://doi.org/10.1111/j.1398-9995.2009.02037.x.

19. Ivanova Jl, Birnbaum HG, Hsieh M, Yu AP, Seal B, van der Molen T, et al. Adherence to inhaled corticosteroid use and local adverse events in persistent asthma. Am J Manag Care. 2008;14(12):801-9.

20. Osterberg L, Blaschke T. Adherence to medication. N Engl J Med [Internet]. 2005;353(5):487-97 Available from: http://www.ncbi.nlm.nih.gov/pubmed/1 6079372.

21. Berg KM, Arnsten JH. Practical and conceptual challenges in measuring antiretroviral adherence. J Acquir Immune Defic Syndr. 2006;43(SUPPL. 1):1-16.

22. Sperber CM, Samarasinghe SR, Lomax GP. An upper and lower bound of the medication possession ratio. Patient Prefer Adherence. 2017;11:1469-78. https://doi.org/10.2147/PPA.S136890.

23. Rolnick SJ, Pawloski PA, Hedblom BD, Asche SE, Bruzek RJ. Patient characteristics associated with medication adherence. Clin Med Res. 2013; 11(2):54-65. https://doi.org/10.3121/cmr.2013.1113.

24. Menckeberg TT, Bouvy ML, Bracke M, Kaptein AA, Leufkens HG, Raaijmakers JAM, et al. Beliefs about medicines predict refill adherence to inhaled corticosteroids. J Psychosom Res. 2008;64(1):47-54. https://doi.org/10.1016/j. jpsychores.2007.07.016. 
25. Apter AJ, Wang X, Bogen DK, Rand CS, McElligott S, Polsky D, et al. Problem solving to improve adherence and asthma outcomes in urban adults with moderate or severe asthma: A randomized controlled trial. J Allergy Clin Immunol [Internet]. 2011;128(3):516-523.e5 Available from: http://dx.doi. org/10.1016/j.jaci.2011.05.010.

26. Bidwal M, Lor K, Yu J, Ip E. Evaluation of asthma medication adherence rates and strategies to improve adherence in the underserved population at a federally qualified health center. Res Soc Adm Pharm [Internet]. 2017;13(4): 759-66 Available from: http://dx.doi.org/10.1016/j.sapharm.2016.07.007.

27. Plaza V, Fernández-Rodríguez C, Melero C, Cosío BG, Entrenas LM, de Llano $L P$, et al. Validation of the "Test of the Adherence to Inhalers" (TAl) for Asthma and COPD Patients. J Aerosol Med Pulm Drug Deliv [Internet]. 2016; 29(2):142-52 Available from: http://www.ncbi.n/m.nih.gov/pubmed/262301 50.

28. Engelkes M, Janssens HM, de Jongste JC, Sturkenboom MCJM, KMC V. Medication adherence and the risk of severe asthma exacerbations: a systematic review. Eur Respir J [Internet]. 2015;45(2):396-407 Available from: http://www.ncbi.nlm.nih.gov/pubmed/25323234.

29. Williams LK, Peterson EL, Wells K, Ahmedani BK, Kumar R, Burchard EG, et al. Quantifying the proportion of severe asthma exacerbations attributable to inhaled corticosteroid nonadherence. J allergy Clin Immunol [internet]. 2011;128(6):1185-1191.e2 Available from: http://www.ncbi.nlm.nih.gov/ pubmed/22019090.

30. Claxton AJ, Cramer J, Pierce C. A systematic review of the associations between dose regimens and medication compliance. Clin Ther. 2001;23(8): 1296-310. https://doi.org/10.1016/S0149-2918(01)80109-0.

31. Bjarnadottir MV, Bjarnadottir MV, Czerwinski D, Czerwinski D, Onukwugha E, Onukwugha E. Sensitivity of the medication possession ratio to Modelling decisions in large claims databases. Pharmacoeconomics. 2018;36(3):369-80. https://doi.org/10.1007/s40273-017-0597-y.

32. Karve S, Cleves MA, Helm M, Hudson TJ, West DS, Martin BC. Prospective validation of eight different adherence measures for use with administrative claims data among patients with schizophrenia. Value Heal [Internet]. 2009; 12(6):989-95 Available from: http://dx.doi.org/10.1111/j.1524-4733.2009. 00543.X.

33. Lester CA, Mott DA, Chui MA. The influence of a community pharmacy automatic prescription refill program on Medicare part D adherence metrics. J Manag Care Spec Pharm [Internet]. 2016;22(7):801-7 Available from: https://www.jmcp.org/doi/10.18553/jmcp.2016.22.7.801.

34. Dima AL, Hernandez G, Cunillera O, Ferrer M, De Bruin M. Asthma inhaler adherence determinants in adults: systematic review of observational data. Eur Respir J [Internet]. 2015;45(4):994-1018 Available from: http://dx.doi. org/10.1183/09031936.00172114.

\section{Publisher's Note}

Springer Nature remains neutral with regard to jurisdictional claims in published maps and institutional affiliations.

Ready to submit your research? Choose BMC and benefit from:

- fast, convenient online submission

- thorough peer review by experienced researchers in your field

- rapid publication on acceptance

- support for research data, including large and complex data types

- gold Open Access which fosters wider collaboration and increased citations

- maximum visibility for your research: over $100 \mathrm{M}$ website views per year

At $\mathrm{BMC}$, research is always in progress.

Learn more biomedcentral.com/submissions 